\title{
EDITORIAL
}

\section{LITERATURA E IMPRENSA}

No início do século XIX, antes que Émile de Giradin e Armand Dutacq (La Presse e Le Siècle, respectivamente) revolucionassem o jornal, tornando-o mais atrativo, econômico e literário, a redação do jornal não dispunha de nenhum protocolo específico, pautando-se por regras da disposição retórica, panfletos, almanaques e, via de regra, o intertexto literário, razão pela qual não só a literatura afluía às redações, de modo a multiplicar a mídia jornalística (as grandes resenhas, revistas, jornais ilustrados, pequenas folhas literárias, jornais infantis etc.), mas também uma grande massa de jovens aspirantes à literatura, tentada a escrever nos jornais e a mobilizar formas literárias já existentes para desenvolver a seção jornalística genérica como era então constituída (THÉRENTY, 2003).

A partir das últimas décadas do século XIX a imprensa torna-se um vetor público de caráter, digamos, uniforme, e seu desenvolvimento responde a uma revolução científica, técnica e industrial - em parte imposta por uma classe burguesa, moderna e cosmopolita, ávida de consumismo. Contudo, a massificação imposta por essa imprensa não foi total, e particularidades afloraram em contextos nacionais. Nas nações pós-coloniais, o jornal adquire força e capacidade de reconfigurar o espaço, particularizando-se ao imprimir certa cor local à sua produção - ainda que sob o peso avassalador dos influxos oriundos das metrópoles europeias -, dinâmica que resultou na reunião de jornalistas, homens de letras, intelectuais, tradutores, livreiros, viajantes etc., às voltas com os órgãos de imprensa local, transformandoos em laboratórios de criação literária e redes para a difusão de saberes e ideias.

O escritor, inserido na esfera midiática, ao pensar e construir seu diálogo com o público, com o mundo dos estereótipos e o discurso social em que está imerso, é levado a um escolho Jangada | nr. 16, jun/dez, 2020 | ISSN 2317-4722 
de palavras, estilo e formas de expressão, no intuito de adequar sua produção singular ao espaço do jornal. Este, por sua vez, leva o escritor a internalizar os novos ritmos sociais, que supostamente são os de uma sociedade democrática e industrializada, mas também da vida quotidiana, que oferece uma imagem tanto mais trivial quanto mais significativa do real e suas ilusões, razão, talvez, da generosa aclimatação dos folhetins nos periódicos oitocentistas.

No Brasil, o aparecimento da imprensa é simultâneo à chegada da corte portuguesa (1808). A despeito dos instrumentos de censura que vigoraram durante todo o período colonial e de o mercado editorial ver-se restringido à cidade do Rio de Janeiro, o progresso da imprensa, ainda que limitado, contou desde o início com o profissional ligado às letras, algo que faz do jornal veículo disseminador da literatura, transformando a prática cultural da leitura, que, ampliada e popularizada, afasta-se das restrições dos gabinetes de leitura.

É nesse contexto que a imprensa, transmissora de cultura, adquire status e papel ativo na mediação dos discursos; ao atuar como dinâmico centro gerador de conhecimento, modifica, estimula e tonifica diferentes pensamentos, ativando certa interdisciplinaridade que engloba não só a comunicação, premissa jornalística, mas também a sociologia, a história e sobretudo a literatura (incluindo-se aqui a tradução de textos de ficção, a crítica literária e todas as vertentes a elas relacionadas), sobretudo se considerarmos que foi no seio dos jornais que parte dos expoentes de nossa literatura - Machado de Assis, José de Alencar, Olavo Bilac, João do Rio, Lima Barreto, Joaquim Manuel de Macedo, Júlia Lopes de Almeida, etc., no século XIX, e Monteiro Lobato, Euclides da Cunha, Clarice Lispector, Nelson Rodrigues, no século XX, dentre tantos outros -, iniciou seu percurso nos jornais.

Nesse contexto, a ideia para o dossiê "Literatura e Imprensa" surgiu da vontade de divulgar o trabalho de pesquisadores cujo teor fosse a interlocução da literatura com jornalismo em suas diferentes modalidades: do texto ficcional (romance-folhetim, conto, poesia, sátira, tradução etc.) ao de opinião (crônica e crítica) e tudo o mais que preencha esse diálogo altamente frutífero para o universo literário. O resultado mostrou-se promissor, dado o número de artigos e a relevância dos conteúdos abordados.

Esse dossiê tem início com o artigo "Resistência intelectual ao nazismo no período de exílio", de autoria de Patrícia Helena Baialuna Andrade, que discorre sobre a produção intelectual de escritores expatriados da Alemanha nazista em periódicos engajados na denúncia contra a violência do nacional-socialismo. Na sequência, "Coisas que só se dizem em latim: a presença de Boileau nas crônicas de Machado de Assis”, de Daniela Mantarro Callipo, se debruça sobre a crônica, esse gênero híbrido, mistura de quotidiano e ficção que, no Brasil, teve Jangada | nr. 16, jun/dez, 2020 | ISSN 2317-4722 
em Machado de Assis um de seus mestres, de modo que Callipo desvela as artimanhas machadianas ao trazer de arrasto Boileau, intertexto assaz pertinente que o cronista lança mão ao comentar o uso polêmico das anquinhas usadas pelas jovens que frequentavam a célebre Rua do Ouvidor. Das anquinhas resgatadas por Callipo, vemo-nos diante d'“Os espartilhos sociais na coluna 'Palestras femininas' de Adelina Amélia Lopes Vieira, no periódico A Semana", de Eduardo da Cruz e Sérgio Abreu, autores que analisam a contribuição da escritora portuguesa, não só ressaltando a "pressão dos espartilhos sociais" na vida das mulheres oitocentistas, mas sobretudo o fazem com "o objetivo de entender o que a autora valorizava sobre perfis femininos de sua época”.

Em "Monteiro Lobato: jornalista multifacetado", Ana Luiza Reis Bedê, por sua vez, resgata o trabalho jornalístico de Monteiro Lobato, muitas vezes obscurecido por sua figura de escritor de sucesso, seu empreendedorismo e sua relevante atuação como editor, de maneira que a pesquisadora não só revela um diletante "sapo da redação", mas também ressalta o desempenho de Lobato como crítico literário e das artes plásticas.

Na sequência, em "Calvário e porres do pingente Afonso Henriques de Lima Barreto, o road movie literário e experimental de João Antônio”, Mariana Filgueiras de Souza analisa a obra de João Antônio, escritor afeito à escrita híbrida literário-jornalística, haja vista manipular o gênero com maestria em seus tempos de colaborador da Revista Realidade, como demonstra a autora. Partindo das visões teóricas de Mikhail Bakthin voltadas para a sátira, a inversão, o riso etc., em "Paródia em jornalismo - o caso do site Sensacionalista", Assunção Cristóvão perscruta a presença da paródia nas matérias publicadas e, a partir disso, identifica o que chama de "pseudonotícias", textos "que se utilizam de um enunciado típico da esfera de atividade jornalística para, por meio da paródia, realizar um movimento centrífugo de desestabilização dos sentidos". Mauro Nicola Póvoas, em “A presença do Brasil e de sua literatura na revista portuguesa A Madrugada (1894-1896)", destaca as características constitutivas dessa publicação que circulava em Lisboa, Portugal, ressaltando a presença de autores brasileiros em suas páginas, dentre os quais, Machado de Assis e Olavo Bilac.

Em "Literatura no jornalismo da Revista piauı̂", Dayane Joyce Lino da Silva e Raquel Beatriz Junqueira Guimarães analisam as articulações entre literatura e imprensa ao destacarem a presença de textos poéticos nas páginas da piauí, o que consideram verdadeira subversão da fronteira jornalística em direção ao literário pelos textos ali publicados. Os dois próximos artigos trazem um pouco da relação literária e cultural Brasil-França na medida em que ou o autor ou a própria imprensa atuam como passeurs culturels: em "A poética do jornal Jangada | nr. 16, jun/dez, 2020 | ISSN 2317-4722 
oitocentista: um cotejo entre Eugène Pelletan e Machado de Assis", de Dayane Mussulini, são investigadas as "reincidências" de leituras compartilhadas entre o escritor e jornalista francês e o Bruxo do Cosme Velho, ressaltando que ambos defendiam "o jornal enquanto espaço democrático e liberal para a transmissão de ideias"; já em "Afinidades, diferenças políticas e consagração: uma análise de críticas literárias sobre romances franceses em 1836”, Márcia Abreu e Beatriz Gabrielli se debruçam sobre os casos específicos dos periódicos La Presse e Le Constitutionnel, ambos rotineiramente lidos aqui no Rio de Janeiro, e que serviam de "palco" para um conjunto de críticas sobre os romances publicados em suas próprias páginas, razão pela qual as autoras concluem que "o estudo permitiu um melhor entendimento sobre a recepção do gênero romanesco nesse período e mostrou que os textos avaliativos oriundos dos periódicos podem ser prolíficas fontes de investigação”.

Na sequência, em “A recepção de Grande sertão: veredas, de Guimarães Rosa, por Paulo Mendes Campos, no contexto jornalístico e das crônicas”, Fabrício Lemos da Costa e Silvio Augusto de Oliveira Holanda atêm-se ao que denominam "recepção de primeiras horas", críticas subsequentes à publicação da obra de Rosa, com a análise de críticas não só de Mendes Campos, mas também de A. Candido, Milliet e outros; já em “"A vida como ela é...', da zona norte à zona sul, pulsa o Rio de Janeiro romântico de Nelson Rodrigues", Leandro Antônio dos Santos traça um panorama de "teor memorialístico-ficcional" do célebre escritor carioca, que em sua coluna jornalística, conclui o autor, constrói uma "visão romântica ao perceber a sociedade carioca, palco de intensas mudanças estruturais, que ainda trazia consigo o pessimismo e a nostalgia da belle époque emoldurando as relações sociais".

Em "Entre jornal e livro: a transposição de $O$ enfermeiro, de Machado de Assis", Yaísa Melina de Araújo e Márcia Gomes Marques investigam o processo de criação desse célebre conto machadiano, revisto em razão da alternância de mídia, de modo a refletirem sobre "os mecanismos da realização artística, [uma vez que estes] permitem abordar a produção ficcional a partir dos meios de comunicação em que estão inseridos".

Para fecharmos o dossiê, trazemos o resgate de duas escritoras cearenses: a primeira, Adília de Albuquerque, emerge em "Pena feminina: a crônica de Adília de Albuquerque na imprensa cearense do início do século XX”, artigo de Carla Pereira de Castro, em que a autora recupera parte da obra da escritora cearense silenciada ao longo da circulação das ideias literárias em um país marcadamente machista e patriarcal; a segunda, Alba Valdez, poeta, escritora, professora, surge em "Alba Valdez na imprensa brasileira", trabalho de Carlos 
Augusto de Melo, Jéssica Aparecida Souza Santos e Keyle Sâmara Ferreira de Souza, que analisam o percurso literário e o engajamento de Valdez materializado em diferentes periódicos.

Na seção Vária, que publica artigos em fluxo contínuo, trazemos "Terra sonâmbula: a (re)construção da identidade do ser africano a partir da língua portuguesa", de Alexandre António Timbane e Ivonete da Silva Santos, que investigam as imbricações da língua do excolonizador entremeadas aos idiomas nativos do Moçambique na construção de novas identidades - ou massacre, para aquelas existentes -, a partir da obra de Mia Couto. "Em busca de si: construção identitária no poema Marabá, de Gonçalves Dias”, Josimere Maria da Silva e Hudson Marques da Silva "promove[m] uma leitura hermenêutico-discursiva" do poema romântico de Gonçalves Dias, a fim de compreender seu “descompasso identitário" (do eu lírico, no caso, a índia Marabá). Em “Um lugar chamado Brick Lane: da subalternidade à construção de uma identidade feminina independente, moderna e insubordinada", Sara Almieira da Rocha e Elis Regina Fernandes Alves apresentam um meritum causae em favor do "feminismo literário" e da emancipação feminina em uma investigação de "textos teóricos que discutem o papel da mulher na sociedade". Ao concluirmos esta seção, adentramos a próxima, com a resenha de igual teor intitulada "Memórias que atravessam a morte: as recordações da violência contra a mulher em Garotas Mortas, de Selva Andrade", na qual Maria Izabella Souza de Lima introduz o leitor à obra da escritora argentina, destacando a luta de Selva Andrade que, por meio da ficção, busca dar visibilidade aos casos de feminicídio ocorridos em seu país.

Antes de concluirmos, gostaríamos de chamar a atenção do leitor para a recorrência de Machado de Assis, autor que perpassa vários dos artigos aqui publicados, o que mostra não só o vigor de sua expressão artística, mas sobretudo a legibilidade de seus contos e crônicas. E é nessa toada que introduzimos a contribuição da Profa. Dra. Lúcia Granja, genuína machadiana, que nos concedeu uma excepcional entrevista para este dossiê. Recentemente, Lúcia Granja publicou Machado de Assis, antes do livro, o jornal: suporte, mídia e ficção (2018), obra que versa sobre o universo abordado neste dossiê, contudo, não se pode deixar de mencionar Machado de Assis, escritor em formação: à roda dos jornais (2000), já considerado referência para os estudiosos de Machado de Assis e também àqueles que se ocupam da literatura nos jornais. Na entrevista, a pesquisadora destaca como a leitura das crônicas machadianas nos próprios periódicos levou-a a melhor “compreendê-las" e "recontextualizá-las", dada "a relação existente entre as crônicas, contos e romances, considerando-se a materialidade e ambiente textual de seu suporte de acolhimento, no que tange a uma revisão crítica do conteúdo dos 
periódicos e a um reaproveitamento das formas". E não é só isso, tem muito mais! Por isso, só nos resta agradecer-lhe e recomendarmos firmemente a leitura.

A todos, uma ótima leitura!

Dirceu Magri - UFV

Alvaro Santos Simões Junior - UNESP

Editores deste número

\section{REFERÊNCIAS BIBLIOGRÁFICAS}

THÉRENTY, Marie-Ève, « Pour une histoire littéraire de la presse au XIXe siècle », Revue d'histoire littéraire de la France, 2003/3 (Vol. 103), p. 625-635. DOI : 10.3917/rhlf.033.0625. URL : https://www.cairn.info/revue-d-histoire-litteraire-de-la-france-2003-3-page-625.htm 